\title{
Nursing home quality of life in the Lebanon
}

DOI:

10.1108/QAOA-01-2016-0002

\section{Document Version}

Accepted author manuscript

Link to publication record in Manchester Research Explorer

\section{Citation for published version (APA):}

Adra, M. G., Hopton, J., \& Keady, J. (2017). Nursing home quality of life in the Lebanon. Quality in Ageing, 18(2), 145-156. https://doi.org/10.1108/QAOA-01-2016-0002

\section{Published in:}

Quality in Ageing

\section{Citing this paper}

Please note that where the full-text provided on Manchester Research Explorer is the Author Accepted Manuscript or Proof version this may differ from the final Published version. If citing, it is advised that you check and use the publisher's definitive version.

\section{General rights}

Copyright and moral rights for the publications made accessible in the Research Explorer are retained by the authors and/or other copyright owners and it is a condition of accessing publications that users recognise and abide by the legal requirements associated with these rights.

\section{Takedown policy}

If you believe that this document breaches copyright please refer to the University of Manchester's Takedown Procedures [http://man.ac.uk/04Y6Bo] or contact uml.scholarlycommunications@manchester.ac.uk providing relevant details, so we can investigate your claim.

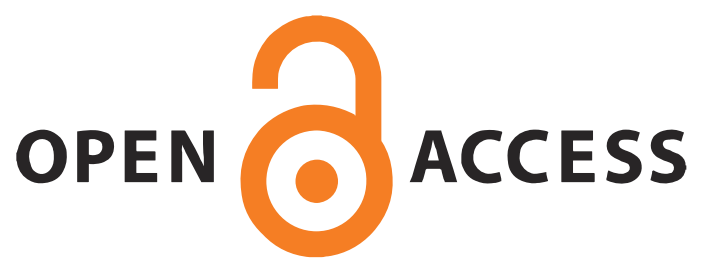




\section{Nursing Home Quality of Life in the Lebanon}

\begin{tabular}{|r|l|}
\hline Journal: & Quality in Ageing and Older Adults \\
\hline Manuscript ID & QAOA-01-2016-0002.R2 \\
\hline Manuscript Type: & Research Paper \\
\hline Keywords: & $\begin{array}{l}\text { Grounded theory, Lebanon, Nursing homes, Older people, Qualitatine } \\
\text { approaches, Quality of life }\end{array}$ \\
\hline \multicolumn{2}{|l}{} \\
\hline
\end{tabular}

\section{SCHOLARONE \\ Manuscripts}


ABSTRACT

Purpose - To explore perceptions, perspectives and meaning of quality of life for a sample of older residents, care staff and family caregivers in two nursing homes in the Lebanon.

Design - A classic grounded theory study was conducted between 2010 and 2011 in two nursing homes in Beirut. Semi-structured interviews were undertaken with a theoretical sample of 20 residents, 8 family caregivers and 11 staff. The constant comparative method was used to analyze the data.

Findings - Three distinct but interrelated properties of quality of life emerged from this process: 'maintaining self', 'maintaining identity', and 'maintaining continuity'. The dynamics that exist within and between each of these properties provide an indicator about shared and distinct meanings and the implications for care practice.

Limitations - The study was conducted in one city in the Lebanon; accordingly, the transferability of findings may be challenging.

Implications for nursing and nursing policy - Improving Lebanese national standards and regulations applicable to nursing home residents may help to enhance residents' care needs and quality of life.

Social implications- There was limited guidance aimed at helping older residents to voice and increase their choice and control.

Originality value - This paper provides new insights to the process of outlining the properties attached to the phenomenon of quality of life in nursing homes in the Lebanon. It will be of interest to those in nursing home care as well as to policy makers.

Keywords Grounded theory, Lebanon, Nursing homes, Older people, Qualitative approaches, Quality of life

Paper type Research paper 


\section{Introduction}

It is estimated that the old-age group currently represents 7.3 percent of Lebanon's population. This is the highest percentage in the region. This is projected to increase to 12.0 percent and 21.0 percent by the years 2030 and 2050 respectively (Sibai et al., 2015). Contemporaneously, the ageing population creates a greater need for nursing services (Bou Harb, 2005) which are often provided in residential care facilities. At present, the demand for the services provided by nursing homes significantly exceeds the current supply and, as a result, the number of nursing homes in the Lebanon is increasing each year due to societal demand (Naja, 2012). In Lebanon, an estimated 1.4 percent of its older population now lives in nursing homes (Naja, 2012). The issue of quality of life carries significant relevance for the residents of such homes; hence the emerging emphasis on issues that determine such factors (Adra et al., 2015).

The aim of this study was to explore the meaning of quality of life as perceived by older residents living in nursing homes in Lebanon, their family caregivers and staff. Knowledge of this phenomenon has the potential to have impact upon the care approaches in this setting and enhance the quality of life for the residents. In this paper the three distinct but interrelated properties of quality of life that emerged from this process are presented.

\section{Review of Literature}

Despite its complexity, lack of a comprehensive definition (Crespo et al., 2012) and authoritative measurement tools (Burack et al., 2012), the concept of quality of life has gained popularity in recent years due to its association with almost every aspect of daily life (Degenholtz et al., 2014). The concept is particularly relevant for residents of nursing homes who are often characterized as being of advancing age, having higher levels of dependency, and being unable/unwilling to complain about poor conditions, or having modest care expectations (Murphy et al., 2007). Research findings regard 
quality of life for older adults as a complex phenomenon related to all aspects of human life, and closely associated with older residents' living conditions (Bowling, 2007). Most investigators have based their concepts and measures of quality of life on experts' opinions, rather than those of lay people (O'Rourke et al., 2015). Consequently, there is little empirical data on the extent to which the existing definition and the items included in most measurement scales have any relevance to people and their everyday lives (Bowling, 2007). There is a general agreement that quality of life is subjective, individualistic and multidimensional, as there are a number of different factors associated with it, all with their own significance (Mollenkopf and Walker, 2007; Bowling et al., 2015). In addition, one's feelings and judgment about his/her quality of life are embedded in his/her personal values, goals, histories, cultures, and life experiences (Kwong et al, 2014).

According to the World Health Organization definition, quality of life is “individuals' perceptions of their position in life in the context of the culture and value systems in which they live and in relation to their goals, expectations, standards and concerns" (WHO, 2016). As a result, measuring quality of life is challenging, especially in the case of older people if they have difficulty expressing themselves and their needs.

In previous studies (Murphy et al., 2007; Cooney et al., 2009), older residents in general from nursing homes in Ireland and south-west England perceived that care environment and ethos care (promoting resident autonomy and choice, promoting and maintaining residents' independence, staff and physical environment), activities and therapies (opportunities to pursue meaningful and purposeful activities), functional status (ability to perform activities of daily living and ability to engage in leisure activities for the sake of pleasure) were important for good quality of life. They also identified some unique concerns for quality of life while living in nursing homes, including connectedness (community, family, and religion), individuality (private space, personal possessions), personal identity (maintaining a sense of self and appearance) and professionalism (working attitude of nurses and individual care) (Kwong et al., 2014). 
Western literature has addressed a variety of objective and subjective indicators of quality of life of older residents (Mollenkopf and Walker, 2007). However, up until the reporting of this study, contemporary research literature has lacked a Middle-Eastern perspective on the meaning and construction of quality of life in nursing homes. The findings of this study, therefore, will bring new insights, and future research will build upon the foundation presented in this study. There is a significant gap in our knowledge about the conditions of older people living in nursing homes in Lebanon (Doumit et al., 2014), and the challenge for the Lebanese society has been the provision of an environment that supports quality of life for residents in these settings. Policy makers, practitioners, and consumer groups need to obtain a preliminary profile on the major health, social and economic problems that are encountered in such environments. Health service users have been identified as the most appropriate people to identify the strengths and limitations of health service provision (Center for Studies on Aging, 2010). Therefore, it is both a timely and necessary step to explore the meaning of quality of life from, first and foremost, the standpoint of the older residents, and second, from other key stakeholders, in order to design and shape supportive programmes that aim at enhancing and personalising service improvement.

Up until the start of this study no comprehensive information existed about the day-to-day lives of nursing home residents in Lebanon (Doumit and Nasser, 2010). This limited the ability of care providers in Lebanon to make evidence-based and informed decisions about everyday care practice. This study has started to map out this territory and explore how nursing home residents, their family caregivers and care staff define quality of life and its distinct and inter-related properties for each of the key stakeholders. In the emergent quality of life model these properties and qualitative methodology are used to underpin model development. 


\section{The study}

\section{Aim}

The overall aim of this study was to explore perceptions, perspectives and meanings of quality of life for a theoretical sample of older people living in Lebanese nursing homes, care staff and visiting family caregivers, and to produce an explanatory theoretical model of experience using the classic approach to generating grounded theory (Glaser and Strauss, 1967; Glaser, 1978).

\section{Design}

Sample and setting: The sample recruited for the study was selected from two nursing homes in Beirut, identified as nursing home $A$ and $B$, where residents included both people with, and without dementia. These homes were selected on the basis of their contrasting bed size and willingness to participate in the study.

Older residents: The sample comprised 11 women and nine men, aged between 65-91 years with a mean age of 73.7 years. Most of the residents had chronic health problems with the main reason for admission being failing physical health and family members' inability to provide care at home. The decision on whether participants would be approached to take part in the study was made in consultation with the geriatrician 'in charge', the family caregiver, the nurse manager, and the researcher's own assessment of capacity to consent. In the course of her nursing practice, the researcher has accumulated experience in taking care of older adults. Moreover, she comes from the same cultural background as the older residents participating in this study and hence she was qualified to assess capacity to consent. Participating residents had lived in the nursing home for a period of between 10 months to nine years and all spoke Arabic. 
Staff members: Eleven staff members were interviewed in total between nursing homes A and B.

The majority were registered nurses $(n=8)$, two of whom were nurse managers, while three of the participants were licensed practical nurses. Eight of the participants were female and three were male, with an age range of between 23-50 years and with clinical experience ranging between one and 14 years. All were permanent paid staff of the nursing home, had been employed for at least six months and spoke Arabic as their first language, and caring for the residents was the main focus of their work. They were identified with the help of the nurse manager in both nursing homes.

Family caregivers: All informants had relatives in one of the nursing homes. A family caregiver was defined as the person most involved in care of the resident who visited the nursing home regularly and had the authority to act as an informal advocate for the resident. The eight family caregivers were aged from 32 to 70 years. While all had cared for their older relative prior to admission to the nursing home, they had visited their relative in the nursing home for a period of one to six years. Family members were identified with the help of the social worker and the nurse manager.

Nursing home A was selected because it has a community reputation for 'admitting complex cases.' It includes four sections for older people, for men and women separately, with a total population of 258 residents. The beds are always permanently occupied by residents. Nursing services are provided by 57 nurses of whom one third are registered nurses, whereas the other staff comprise nursing assistants, and a team of social workers and ergo therapists. The main objective of this long-term care institution is to ensure health, medical and nursing care, and social services to older residents.

Nursing home B provides traditional care and has a 70-bed capacity. It is a non-profit organisation and seeks the provision of comprehensive health and social services to its older residents. The home provides medical care, nursing care, social and recreational care, rehabilitation, rest, and security. The activities of nursing home B are carried out by a multi-disciplinary team of health care professionals including 40 full-time staff members, two medical doctors, and three part-time staff 
members. All residents are visited twice daily by the geriatrician, and a comprehensive geriatric assessment is conducted as a weekly follow-up. The necessary treatments are administered to those needing them, while the follow-up on prescribed treatments is ensured by the nursing staff on a 24hour basis.

Ethical Considerations: Permission to conduct the study was granted by the Institutional Review Board (IRB) and Ethics Committee in two universities: The American University of Beirut (reference: NUR.MA.02) and The University of Manchester, UK (reference: 09/1021/NMSW). This was necessary as the first author was receiving research supervision from staff at The University of Manchester (JH and JK in the authorship). The IRB recommended that a witness be present during the process of gaining consent from the older residents, since the study focused on a vulnerable population that may be living with a dementia. In the event, all participants gave written consent to take part in the study. Assurances of confidentiality and anonymity were provided at the time of entry into the study and such anonymity is preserved in this article whenever quotations are used.

Data Collection and Analysis: This study commenced with an appreciation that there was limited understanding about resident quality of life in the Lebanon (Doumit and Nasser, 2010). This underresearched area was therefore one suited to investigation using classic grounded theory (Glaser and Strauss, 1967; Glaser, 1978) as theory and theory development are grounded in empirical data and in acts of everyday social life, such as that experienced in the nursing home.

The principal method of data collection was semi-structured interviews. This method was chosen so that participants could tell their story in their own words within a loose but time-limited structure. Early interviews focused on encouraging participants to tell their stories whilst later interviews became more focused as concurrent data analysis guided further data collection. All interviews were conducted by the first author in colloquial Lebanese (the participants' mother tongue), and were conducted in a private location at the nursing home. Interviews were digitally tape-recorded and lasted between 35 and 60 minutes. 
The audio taped interviews were transcribed and translated into English by a nurse holding a Master's degree in nursing who was fluent in both languages. The first author listened to the recordings, checked the transcriptions for accuracy and contextual meaning, and re-edited them where necessary. The final set of transcriptions (Arabic-English) was checked once again by an academic colleague at the American University of Beirut who was proficient in both languages.

Each interview was read completely at first, then line by line. Holistic reading allowed the identification of main statements on the participant's experience. This provided the first author with an opportunity to interact with details embedded in the data and thereby to grasp the underlying meaning of these data.

The key ideas were translated into more abstract concepts. The author then developed a set of tentative coding categories and pinpointed examples of respondents' statements indicative of these categories. The next step in the analysis process involved examining the relationships between categories and properties of indicators for quality of life in terms of contexts, actions, interactions, and consequences. Theoretical memos were kept by the author following each interview and their use helped to shape the process of data analysis, particularly in the search for basic social processes and their role in explaining relationships in the data. As the categories began to fill, those that were most dense became core categories (Glaser, 2001) which conceptualized relationships between the identified categories and their properties. Then, the researcher raised the conceptual level of those ideas towards developing theory. Developing theory from interview data was achieved by constant comparison, comparing incidents against other incidents in the data for similarity and difference (Glaser, 1978). Consequently, the process of theory development stemmed from the analysis of interview data and constant comparison of incidents, supported by observation, field notes, ongoing literature review and analysis of memos (Hunter et al., 2011).

In the presentation of quotations in the findings section, the resident is represented by the letter R; staff by S; and family by F. A number indicates the interviewee allocation. The nursing home location 
is identified by placing the letter A [representing nursing home A] or B [representing nursing home B] at the end of the code.

\section{Findings}

Constant comparative analysis of data generated led to the emergence of three interrelated properties of process: 'maintaining self', 'maintaining identity', 'maintaining continuity' which support the foundations of quality of life and explain the experience of the older resident, the staff member, and the family caregiver in their movement towards achieving and sustaining this goal. Figure 1 provides a visual representation of these relationships and the findings are discussed in this diagrammatic context.

\section{Insert Figure 1 About Here}

\section{Maintaining self}

'Maintaining self' involved the recognition of older residents as persons, as well as their ability to maintain their previous experiences and to express their identity. According to all participants, 'maintaining self' was integral to enhancing the quality of life of the older residents and included such properties as health and functional well-being, maintaining safety, forging new ties, participating in purposeful activities, and the continuity of spiritual comfort. Residents shared a belief that 'maintaining self' brings about life satisfaction and described how 'good care' helped to preserve their everyday life pattern and sense of personal esteem. For example, R3-B was reserved and professional in his manner. He spent hours sitting and watching others in the nursing home lobby. Upon approach, he was a warm and gentle man and shared the following observation:

"I am happy when I am healthy and independent. I always exercise, eat healthy food and talk with people and discuss with them health problems, and, of course I pray every day, 
sometimes I attend church services and I get spiritual comfort. This is quality of life. I don't want to be dependent on anybody, the ability to carry out significant tasks greatly matters to $m e^{\prime \prime}$.

Most of the residents shared similar stories. For instance, R 11-A, a female resident, said:

"I stay with the residents who have no family to check on them. Take the lady who is sitting in front of us. I keep her company at times so she doesn't get bored. I want to bring her comfort. I am the type of person who goes to the residents' rooms to and see how they are doing. I kiss them, tell them stories. Even men. They do enjoy it a lot. Helping to take care of others is my second nature, the preservation of personal relationships plays a major role in my existence."

Older residents derived a sense of being useful from helping fellow residents they believed to be more disabled than themselves.

Staff thought that 'maintaining self' involved an understanding of the residents' perspectives and feelings, and was a necessary basis for constructive helping relationships. Staff believed that caregiving was a social duty and should occur in a relationship in which the resident and the nurse established good everyday knowledge about one another:

"Nurses should love older people in order to work with them; they should spend time with them. I wish schools of nursing would raise awareness in nursing students about this growing population in our country. Imagine that they give birth to us, help us to start our lives and now we are helping them to finish theirs. My mother and father helped me face the world and succeeded; they helped me build myself and start on my own, and now I am helping them to die in return. Do you see the difference?" (S7-A) 
“Relationships between residents and staff are essential to residents' experiences in nursing homes. Strong and positive relationships between nurses and residents is of great importance for some residents and influences their 'life's meaning". (S1-B)

Families saw themselves as providing links with the outside world and with the resident's past; thus, helping to maintain the resident's sense of self. Some family caregivers were willing to provide whatever care they could:

"When I am here my role is, if she needs to go to the bathroom I'll take her, if she needs to change her clothes I'll help her do that, I help her while eating, and I tell her about her grandchildren." (F2-A)

Many family caregivers stated that their responsibility to the residents was 'to be their voice,' 'to fight their battles for them,' and to be a 'mediator', so that they could ensure 'proper care,' 'good care,' and 'that the physical and psychological needs of the residents were looked after', thus maintaining their sense of self.

\section{Maintaining Identity}

Maintaining identity encompassed considering each resident as a real person rather than as a diagnostic category, as well as working with each older resident as an individual with a life history that is significant, remembered, and cherished. Maintaining the resident's identity represented an essential property of quality of life for the participants. Factors that had an impact on maintaining identity included: fostering respect and well-being, creating a home-like environment, delivering quality care, and encouraging participation in meaningful activities. During the interviews it became apparent that residents who were used to being independent were apprehensive about experiencing chronic disability that would make them heavily dependent, making their quality of life poorer: 
"In the past I used to run a business and then I had this stroke thing which has kept me down; I had to give the business up in the end. I was really sorry about that. It really affected me." (R19-B)

On the other hand, residents who needed a lot of help with daily activities strove to accept their situation:

"My quality of life now consists of adjusting to my current condition. When I have thoughts about my past life I feel upset, but then I accept reality and God's will. I say to myself that I have no other choice than accepting my situation as is, my daughter got me my favorite movies I watch them and this is how I get satisfaction." (R8-B)

Staff considered the concept of respect to be a key element in their interaction with residents and crucial to maintaining the resident's identity. This was evident through staff acknowledging the resident's concerns and including them in decision-making:

"I think from the time they are admitted you have to make them feel that they are respected, they are individuals, and that you just want to help them, maintaining the older residents' identity represents an essential determinant of his life satisfaction." (S4-A)

\begin{abstract}
Acknowledging the older person's concern or distress was also considered to be a form of empowerment while the extent to which a resident felt empowered had a significant impact on the resident's identity:
\end{abstract}

"I think empowering starts right from the minute the resident is admitted to the nursing home, even for somebody who has very little control. There are small ways you can empower them by giving them choices. For example, you can give them a choice between wearing their own clothes or wearing those provided by the institution. I think that is empowering them." 
Family caregivers sought a personalized relationship with the staff in the sense that the care team had an empathic understanding of the caregiver's situation. In the absence of a personalized relationship, it was more difficult for family caregivers to believe that their experience was understood and considered important by the health care providers:

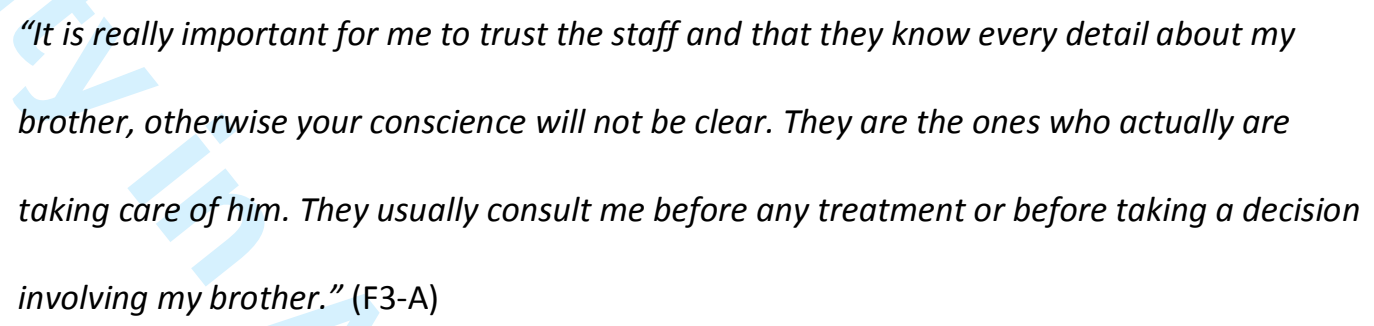

For certain families, attention paid by staff to their loved one's tastes and habits could make a major difference in their perception of both personalized care and being listened to in order to assure maintaining the identity of their loved one.

\section{Maintaining continuity}

Maintaining continuity implicated staff supporting and facilitating family visits, staff-relative partnership, staff responsiveness to family caregiver's knowledge, empathic awareness, and personalized care for the older relative. This property was associated with staying in contact with the family, receiving personalized care, living in a safe and homely environment, and family and staff collaboration. Continuity was maintained by the family through maintaining their emotional bond by providing residents with regular updates about family events and by continuing pre-established care giving activities. In the family caregivers' view, they were experts on the needs, values, and expectations of their relative. The most positive experiences were when family caregivers remained involved in direct care of their relative by working in partnership with staff to ensure that their relative's views and opinions were taken into account when planning their care. 
Evoking past achievements had an invigorating effect on some residents. They referred to a life of 'independence' and 'hard work' they had previously lived, but the loss of both created a vacuum and uncertainty about a future that would be partially determined by others:

"I spent my life sewing for people and then I had this stroke thing. Now I am sitting here and feeling bored, I would like to continue what I have been doing in the past". (R7-B)

Staff mentioned that the majority of older residents enjoy talking about their lives, and that being listened to afforded 'personhood, identity and significance' to the resident. They considered maintaining the continuity of the residents' sense of self as central to upholding their quality of life. Staff described examples of care that involved 'doing something' for a resident that was important to them individually. The following example illustrates the case of a resident who enjoys listening to classical music and is given the opportunity and means to do this:

"There is this older resident who loves listening to classical music. I have arranged for him to buy a tape recorder so he will be able to listen to classical music, it is very important for the older resident to maintain the lifestyle before being admitted to the nursing home". (S2-B)

While some family members only visited their relative, there were others who participated in the communal life of the nursing home and whose contribution to the communal life was valued by other residents and staff. In turn, staff made it clear that they valued their contributions to the home community, while family caregivers understood that staff had to maintain continuity with all the residents:

"I think the staff attitude has changed a lot. Before, they just used to deliver physical care to my father, but now they are talking to him more. I think their relationship is better, and regarding communication, there has been a big progress. Now there is respect; they encourage the verbalization of feelings; they prioritize nursing care activities in response to the residents' care needs, they also attend to their psychosocial needs." (F7-B) 


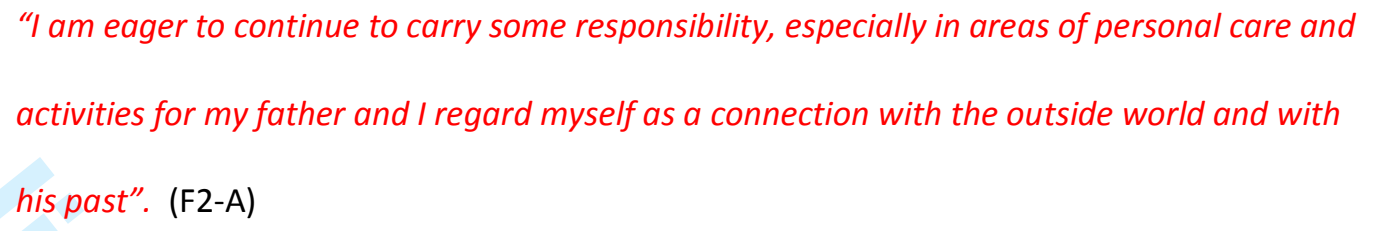

In the nursing home, the advocacy role of the family caregiver appeared to be characterized by serving as role model in the fulfillment of certain tasks, developing relationships with the staff to make a commitment with them to resolve problems, and monitoring the care of their relative. As such, 'maintaining continuity' had future-looking properties that upheld the importance of quality of life as the resident's needs changed over time.

\section{Discussion}

The present study collected data on resident's quality of life from three different sources: the resident, the family caregivers, and the care staff in the nursing home(s). The emergent model seen in Figure 1 suggests that quality of life is a dynamic, personal construction that is enhanced by maintaining self, identity and continuity. When residents are unable to sustain these social actions, quality of life is diminished. For example, as seen in the data, older residents enhanced their quality of life when they watched their favorite movie, engaged in communal singing. These seemingly mundane everyday events are powerful affirmations of self, identity, continuity that become an opportunity to maintain well-being and quality of life.

Despite the limited educational and research base for older people in the Lebanon, the findings of this study support previous research from the West that highlight the complexity of the concept of quality of life (Crespo et al., 2012). For example, the findings highlight the importance of relating oneself to the personal living environment by spatial orientation, contentment with daily routines and maintaining personal safety. Residents maintained social continuity via updates on their children's and grandchildren's activities, birthdays, and accomplishments, and on daily news. 
Preserved relationships inside and outside the nursing home had a positive impact on quality of life, as also reported in other studies (Cooney, 2012).

To create a sense of self and identity staff needed to understand significant moments in the resident's life. As staff listened to family caregivers telling stories about the resident's lives, they began to understand how significant moments influenced the residents' daily life. Storytelling has been found to encourage staff to see beyond the immediate physical needs of residents and to ensure significant details were included in personal care routines (Brown Wilson and Davies, 2009), and individualize the care of the resident. This suggests that reflecting what is significant to a resident in their care, not only contributes to improved quality of life but may also promote a sense of purpose for staff. Indeed, Degenholtz et al. (2014) demonstrated that an individualized assessment and care planning system can produce meaningful and lasting improvements in resident quality of life.

Developing personal knowledge about the resident enabled staff to create a sense of continuity. According to Newson (2011), recognizing a resident's personhood is a way of maintaining their identity, and is key to forming effective caring relationships with them. Staff described how they initiated conversations about a resident's past which gave the resident pleasure and made them feel as if they were able to deliver a more personalized and holistic form of care.

Developing an increased sense of self and identity and personal safety since moving into the nursing home is underlined by the residents and their family. The findings of Kwong et al. (2014) show a relationship between experiencing a sense of comfort and safety on the one hand, and quality of life on the other. This was also linked to a sense of belonging, security, independence, and purposefulness (Cooney, 2012; Kwong et al., 2014). Comfort and security promoted peace of mind in the resident, thus enabling them to personalize their own living area and thereby enhance their wellbeing. This exploration of quality of life in residents in a nursing home milieu evident in this study is 
reflected in other literature on related themes (see for example Bowers et al., 2009: Brown Wilson et al., 2013).

Leahy (2013) confirms that participating in meaningful activities such as arts programs improved quality of life under the domains identified in the quality of life literature, such as sense of self, identity, continuity. Family caregivers also suggested that the nursing home should be 'homelike' and that the environment should move away from large communal spaces which made it feel 'institutional'. They also stressed that residents should be more involved in decision making processes. The need for nursing home environments to be more homelike was also identified by Murphy (2007) and Nasser and Doumit (2011) who suggested that such environments were more likely to be friendly, interpersonally safe and relaxed.

To enhance quality of life, maintaining self, identity, and continuity for the residents can be met by implementing self-care routines that are similar to the person's past routines and habits (Register and Scharer, 2010). This study also suggests that more flexible daily routines which assimilate the biographical preferences of the resident will impact on the person's quality of life, a finding echoed in the international literature (Cooney, 2012; Leahy, 2013). Similarly, Edvardsson et al. (2010) suggest that nursing home staff should be encouraged to plan care in accordance with the residents' needs, and not their own, and that the fulfillment of tasks should not take priority over time spent with the residents and their family caregivers.

The 'maintenance of self' comprises many different dynamics such as the bond to the family, community, nature, the Creator, land, environment, ancestors, and traditional lifestyle and spirituality. Spirituality, though often ambiguous, has a definite impact on who we are, what we become, and how this is accomplished (Williams, 2008). Moreover, previous research findings suggest that spirituality contributes significantly to hope (Erichsen and Bussing, 2013), and is linked to positive states of well-being, a reduction in depression and morbidity, and an increased life expectancy of residents (Burack et al., 2012). Interpersonal relationships, sense of belonging, 
connectedness with a higher being or some purpose greater than self, may be especially important in the lives of residents and their families (Hill, 2006), especially in the Middle Eastern cultural context.

Finally, quality of life was sustained and restored by the types of relationships residents held with fellow residents, staff, their families, and the community, and was related to residents achieving each of the properties displayed in figure 1. Consequently, as seen in this study, nursing care involves finding ways to facilitate and support these three properties among the three stakeholder groups.

\section{Study limitations}

The findings of this study are limited by sample size and setting, namely two nursing homes in Beirut. The sample is comprised of more able residents and it is therefore unknown whether the findings apply in the same way to all residents. Moreover, the nursing homes participating in this study were chosen for their geographical accessibility and their willingness to take part in the research and may not represent the 'typical' nursing home in Lebanon. Another limitation of the study could be due to the translation process of the interviews where some interpretations may have been lost.

\section{Implications for nursing practice and policy}

On the basis of the findings presented in this article, a number of strategies could be implemented in practice. Staff members' flexibility with respect to timetables and options allows the residents to enjoy a higher measure of autonomy. The reduction of the number of persons per room may also ensure better privacy and mitigate the problems of noise, light, and disagreements.

The findings of the study and specifically the importance of maintaining self, identity, and continuity should be incorporated within the nursing curricula and the continuing education programmes to help develop better familiarity with the older residents needs in a nursing home milieu. Nursing 
homes should be acknowledged as learning environments for nursing staff and students; however, their teaching role needs to be enhanced with increased financial investment.

These findings about quality of life and the residents' priorities have implications for the staff members and for optimal practice. Firstly, the findings about the importance of family members' visits indicates that it is desirable to promote open-door visiting policies, with the allocation of proper visiting spaces that respect privacy in nursing homes. This in turn can facilitate nursing home staff encouraging family members to participate in the life and culture of the nursing home. The involvement of family caregivers in nursing homes should be encouraged and seen as a measure of good practice.

The authors suggest, on the basis of the findings reached in this article, that nurses providing long term care reassess their perception of the role of family caregivers and develop new ways of working with them; recognising their role as partners in care who have a lot to contribute to promoting understanding of their relatives' strengths and needs and what would make their lives in care more comfortable and satisfying for them. A more fundamental issue is the type of relationships between family caregivers and the nurses that can lead to this type of partnership. Very clear statements were made in this study by family members; they wanted relationships in which they could express their ideas freely as well as listen to the perspectives of staff. Specifically, they expected the nurses to listen attentively to them and take into account their comments, objections, and suggestions. In summary, the collaborative efforts made by the nursing staff and family caregivers should be channelled into building and cementing a trusting relationship between them.

The authors also suggest that the scope of nursing home activities be broadened and customised to reflect the personal interests, needs and life history of each resident and that occupational cultures that are too driven by routine and fixed time schedules should be replaced with more flexible approaches to daily living. 
The Lebanese national standards and regulations applicable to nursing home residents should be improved to allow for the fulfilment of residents' care needs, such as the creation of a home-like design.

\section{Conclusion}

The findings suggest that quality of life is a complex phenomenon and that recognizing the role of 'maintaining self, identity, and continuity' in the care process is crucial to improving the quality of life of nursing home residents in the Lebanon. An important consideration than can be drawn from the findings of this study is the perception of the older residents as not only patients, but also as persons who deserve to live the last days of their life in dignity and to be treated with respect in an empowering and enabling milieu, away from undermining conduct. It is incumbent on policy makers, nursing management, and staff members to embrace change and define their roles in the context of advancing the quality of life of the older residents. The substantive grounded theory that was developed in this study has led to an accessible theoretical model that takes into account nursing actions. The model can be useful to nurses in enabling them to conceptualize and develop practice approaches from a scientific foundation and in meeting the needs of residents in similar contexts. Undertaking further qualitative studies on frail residents is likely to offer a better perception of the path leading to well-being and its intersection with quality of life. These studies can be used as a means for the assessment of the policies and practices followed by the stakeholders. 
Figure 1. Quality of Life and its Properties of Process

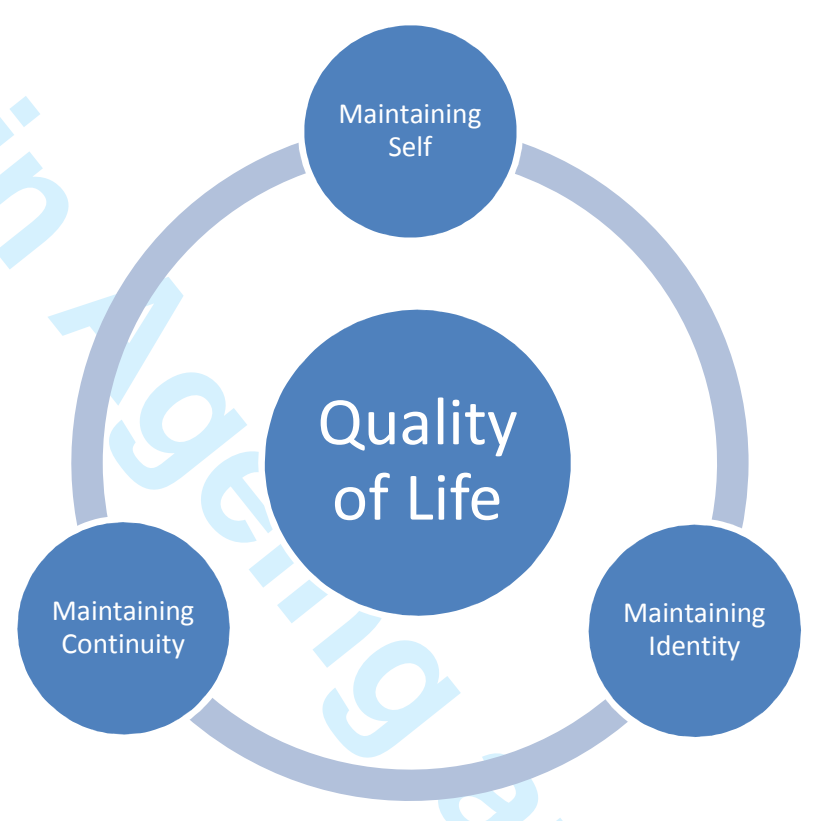

33

34

35

36

37

38

39

40

41

42

43

44

45

46

47

48

49

50

51

52

53

54

55

56

57

58

59

60 


\section{References}

Adra, M. G., Hopton, J. and Keady, J. (2015), “Constructing the meaning of quality of life for residents in care homes in the Lebanon: perspectives of residents, staff and family", International Journal of Older People Nursing, Vol. 10 No. 4, pp. 306-318.

Bou Harb, R. (2005), “Chronique sociales”, Annales, Travail Social et Recherche, Vol. 7 No. 21, 20042005. Beirut: Universite Saint-Joseph.

Bowers, H. et al. (2009), Older People's Vision for Long-Term Care, York: Joseph Rowntree Foundation, available at: $\underline{\text { http://www.jrf.org.uk/report/older-peoples-vision-long-term-care }}$ (accessed 3 December 2015).

Bowling, A. (2007), "Quality of Life in Old Age", in Mollenkopf, M. and Walker, A. (Eds), Quality of Life in Old Age: International and Multi-Disciplinary Perspectives. (pp. 15-30), Springer Netherlands.

Bowling, A., Rowe, G., Adams., S., Samsi, K., Crane, M., Joly, L., Manthrope, J. (2015). Aging and Mental Health, 19 (1), pp. 13-31.

Brown Wilson, C. and Davies, S. (2009), “Using relationships in care homes to develop relationship centred care- the contribution of staff", Journal of Clinical Nursing, Vol. 18, pp. 1746-1755.

Brown Wilson, C., Swarbrick, C., Pilling, M. and Keady, J. (2013), "The senses in practice: enhancing the quality of care for residents with dementia in care homes", Journal of Advanced Nursing Vol. 69, pp. 77-90.

Burack, O.R., Weiner, A.S., Reinhardt, J.P. and Annunziato, R.A. (2012), “What matters most to nursing home elders: Quality of life in the nursing home", Journal of the American Medical Directors Association, Vol. 13 No. 1, pp. 48-53. 
Center for Studies on Aging, (2010), "Services for older adults", available at:

http://www.csa.org.lb/en/default.asp?menulD=4 (accessed 2 February 2012).

Cooney, A. (2012), “'Finding home': a grounded theory on how older people 'find home' in long-term care settings", International Journal of Older People Nursing, Vol. 7, pp. 188-199.

Cooney, A., Murphy, K., and O'shea, E. (2009), “Resident perspectives of the determinants of quality of life in residential care in Ireland", Journal of Advanced Nursing, Vol. 65 No. 5, pp. 1029-1038.

Crespo, M., Bernaldo de Quirós, M., Gómez, M. and Hornillos, C. (2012), “Quality of life of nursing home residents with dementia: A comparison of perspectives of residents, family, and staff", The Gerontologist, Vol. 52 No. 1, pp. 56-65.

Degenholtz, H.B., Resnick, A.L., Bulger, N. and Chia, L. (2014), “Improving quality of life in nursing homes: the structured resident interview approach", Journal of Aging Research, pp.1-8.

Doumit, J.H., Nasser, R.N. and Hanna, D.R. (2014), “Nutritional \& health status among nursing home residents in Lebanon: comparison across gender in a national cross sectional study", BMC Public Health, Vol. 14, pp. 629.

Doumit, J. and Nasser, R. (2010), "Quality of life and wellbeing of the elderly in Lebanese nursing homes", International Journal of Health Care Quality Assurance, Vol. 23 No. 1, pp. 72-93.

Edvardsson, D., Fetherstonhaugh, D. and Nay, R. (2010), "Promoting a continuation of self and normality: Person-centered care as described by people with dementia, their family members and aged care staff", Journal of Clinical Nursing, Vol. 19, pp. 2611-2618.

Erichsen, N.B., Bussing, A. (2013), "Spiritual needs of elderly living in residential/nursing homes", Evidence Based Complementary and Alternative Medicine, Vol. 2013, pp. 1-11.

Glaser, B. G. (1978), Theoretical Sensitivity, The Sociology Press, Mills Valley 
Glaser, B. G. and Strauss, A. L. (1967), The Discovery of Grounded Theory: Strategies for Qualitative Research, Aldine Transaction, London.

Hill, D.L. (2006), "Sense of belonging as connectedness, American Indian Worldview, and Mental Health", Archives of Psychiatric Nursing, Vol. 20 No. 5, pp. 210-216.

Hunter, A., Murphy, K., Grealish, A., Casey, D. and Keady, J. (2011), “Navigating the grounded theory terrain. Part 1", Nurse Researcher, Vol. 18 No. 4, pp. 6-10.

Kwong, E.W., Lai, C.K. and Liu, F. (2014), "Quality of life in nursing home settings: Perspectives from elderly residents with frailty", Clinical Nursing Studies, Vol. 2 No. 1, pp. 100-110.

Leahy, A. (2013), “'A window opening up?' The contribution of arts programmes to quality of life for older people living in care-homes in Ireland", UNESCO Observatory Multi-Disciplinary Journal in the Arts, Vol. 31 No. 3, pp. 1-22.

Mollenkopf, H., and Walker, A. (2007), "Quality of life in old age", in Mollenkopf, M. and Walker, A. (Eds), Quality of Life in Old Age: International and Multi-Disciplinary Perspectives, Springer, pp. 235248.

Murphy, K. (2007), “A qualitative study exploring nurses' perceptions of quality care for older people in long-term care settings in Ireland", Journal of Clinical Nursing, Vol. 16 No. 3, pp. 477-485.

Murphy, K., O’Shea, E. and Cooney, A. (2007), “Quality of life for older people living in long-stay settings in Ireland", Journal of Clinical Nursing, Vol. 16 No. 11, pp. 2167-2177.

Naja, N. (2012), "Long-term stay institutions in Lebanon", The Lebanese Medical Journal, Vol. 60 No. 4, pp. 252-256.

Nasser, R. and Doumit, J. (2011), “Developing criteria for elderly nursing homes: the case of Lebanon", International Journal of Health Care Quality Assurance, Vol. 24 No. 3, pp. 211-222. 
Newson, P. (2011), "At home then away: supporting new residents as they settle in", Nursing and Residential Care, Vol. 13 No. 1, pp. 32-35.

O’Rourke, H.M., Fraser, K.D., and Duggleby, W. (2015), "Does the quality of life constructs as illustrated in quantitative measurement tools reflect the perspective of people with dementia?", Journal of Advanced Nursing, Vol. 71 No. 8, pp. 1812-1824.

Register, E.M. and Scharer, K.M. (2010), “Connectedness in community-dwelling older adults”, Western Journal of Nursing Research, Vol. 32 No. 4, pp. 462-479.

Sibai, A., Rizk, A., and Kronfol, N.M. (2015), "Aging in Lebanon: perils and prospects", Lebanese Medical Journal, Vol. 63 No. 1, pp. 2-7.

WHO (World Health Organization). 2016. Dementia: A public health priority. Retrieved February 7, 2016 from http://www.who.int/mediacentre/factsheets/fs362/en/

Williams, B.J. (2008), "An exploratory study of older adults' perspectives of spirituality", Occupational Therapy in Health Care, Vol. 22 No. 1, pp. 3-19. 
Figure 1. Quality of Life and its Properties of Process

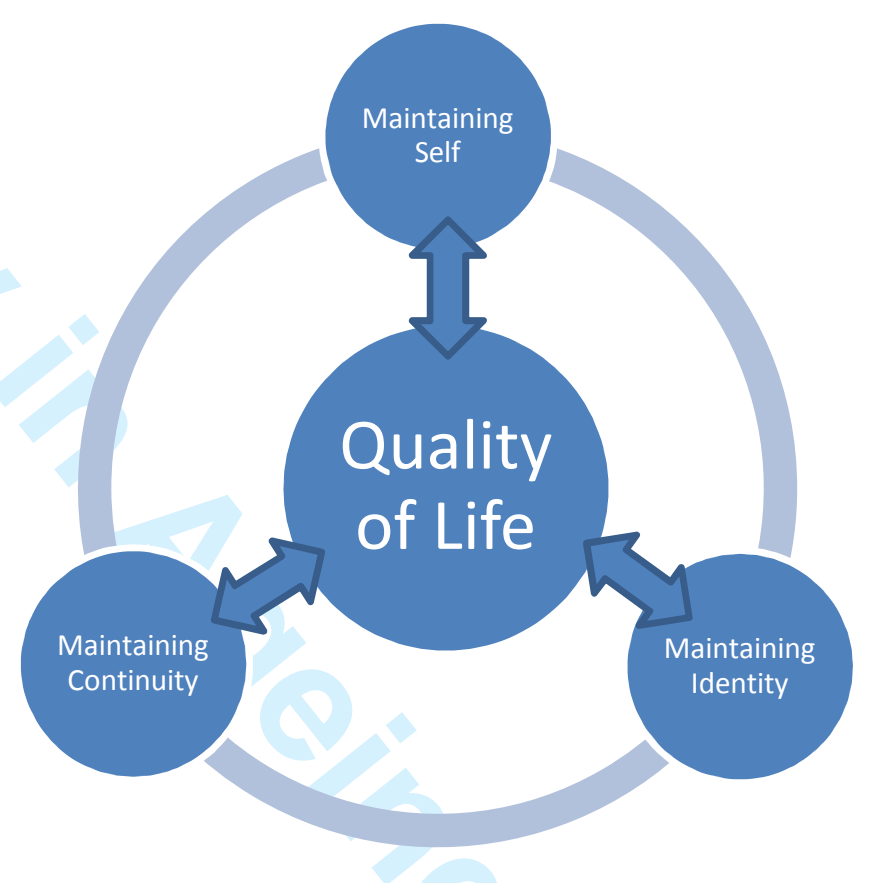

29

30

31

32

33

34

35

36

37

38

39

40

41

42

43

44

45

46

47

48

49

50

51

52

53

54

55

56

57

58

59

60 


\section{Older Resident}

1) How would you describe quality of life?

2) What do you understand by the term "quality of life"?

3) What kind of things does the term quality of life make you think of?

4) Tell me what is important to you living in this nursing home?

5) What do you like most about being in this nursing home?

6) What kind of activities do you enjoy most here?

7) What are the 3 or 4 things you feel essential for having a good quality of life living in this nursing home?

8) What in your current life is going well?

9) If anything what could make your life feel better?

10) What do you look forward to in the day/week?

11) What kind of things do you miss about your life before you moved in here?

\section{Staff Member}

1) What do you understand by the term "quality of life"?

2) To what extent do your residents here enjoy that sort of "quality of life"?

3) What things are important to a good quality of life for the older persons living in this nursing home?

4) How do you measure good quality care in your nursing home?

5) What do you do in your work here to ensure residents enjoy a good quality of life?

6) What mechanisms do you have in place to check that those interventions are effective?

7) What else could nurses do to help in creating a good life for older persons living in this nursing home?

8) What other things would you like to be able to do to enhance the residents' quality of life?

9) What prevents you from being able to do those things?

\section{Family Carer}

1) How would you describe quality of life?

2) What is your life like now, now that your relative is in a nursing home?

3) What do you think makes a good quality of life for your relative living in this nursing home?

4) If anything, what could improve your relative's life?

5) Can you describe your role in helping to support quality of life of your older relative?

6) Do you still think of yourself as a carer? If so, in what way?

7) What, if any, pleasure do you get from visiting your relative in the nursing home?

8) How would you describe your relationship with your older relative?

9) How much support are you given by health care professionals?

10) How often do you receive any practical support you need?

11) How satisfied are you with the treatment that your older relative receives?

12) What factors did you think about when you were choosing a suitable nursing home/helping your relative choose a suitable nursing home? 